\title{
Deficiências minerais em animais de fazenda, principalmente bovinos em regime de campo ${ }^{1}$
}

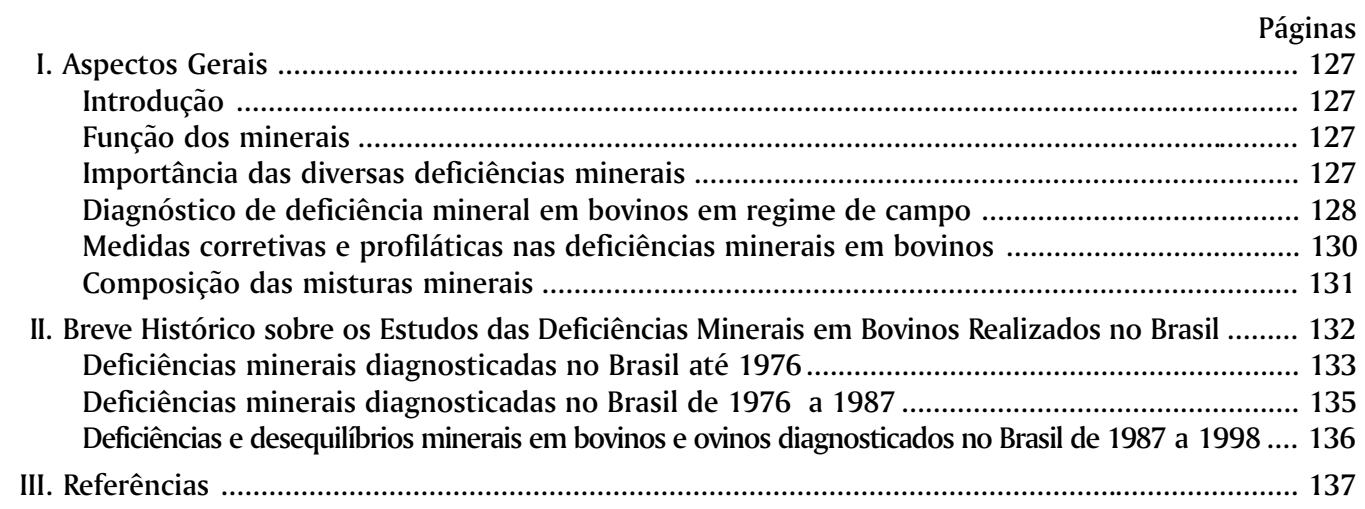

\section{ASPECTOS GERAIS}

Introdução

Em muitas partes do mundo, grande quantidade de animais de fazenda consomem dietas que não correspondem as suas necessidades em relação aos minerais. Os alimentos podem ser ricos ou pobres em determinados elementos, mais frequentemente pobres, ou os contêm em proporções desequilibradas entre si.

As deficiências minerais podem ocorrer sob diversos graus, desde deficiências severas, com perturbações mais ou menos características, até deficiências leves, com sintomas não-específicos, como desenvolvimento lento, problemas de fertilidade, baixo rendimento da carcaça e pouca produção de leite.

As deficiências minerais estão ligadas a certas áreas geográficas. Quando acentuadas, podem ser responsáveis pela pobreza geral que existe em determinadas regiões, onde a população depende principalmente da criação de gado. Deficiências leves ou moderadas também podem causar prejuí-

\footnotetext{
${ }^{1}$ Artigo revisado e ampliado da publicação Tokarnia C.H., Döbereiner J. \& Peixoto P.V. 1998. Deficiências minerais em animais de fazenda, principalmente bovinos criados em regime de campo, p. 11-22. In: Gonzalez, F.H.D., Opina H., Barcellos J.O.J. (Ed.) Nutrição Mineral em Ruminantes. $2^{\mathrm{a}}$ ed. UFRGS, Porto Alegre, RS.
}

zos econômicos sérios, porque reduzem a produtividade dos animais e constituem obstáculo à melhoria dos rebanhos.

Função dos minerais

Os minerais desempenham três tipos de funções essenciais para o organismo dos animais e do homem. A primeira delas diz respeito a sua participação como componentes estruturais dos tecidos corporais (por exemplo Ca, P). Também atuam nos tecidos e fluidos corporais como eletrólitos para manutenção do equilíbrio ácido-básico, da pressão osmótica e da permeabilidade das membranas celulares ( $\mathrm{Ca}, \mathrm{P}, \mathrm{Na}, \mathrm{Cl})$. Por último, funcionam como ativadores de processos enzimáticos $(\mathrm{Cu}, \mathrm{Mn})$ ou como integrantes da estrutura de metalo-enzimas $(\mathrm{Zn}, \mathrm{Mn})$ ou vitaminas $(\mathrm{Co})$.

Importância das diversas deficiências minerais

Para situar o problema das deficiências minerais em relação aos bovinos, convém fazer-se um breve comentário sobre cada um dos minerais essenciais. De acordo com os conhecimentos atuais, dos cerca de 50 minerais que o organismo contém, somente os seguintes são essenciais aos processos metabólicos e por isso mesmo devem estar presentes na alimentação: $\mathrm{Ca}, \mathrm{P}, \mathrm{Mg}, \mathrm{K}, \mathrm{Na}, \mathrm{Cl}, \mathrm{S}, \mathrm{Fe}, \mathrm{Co}, \mathrm{Cu}, \mathrm{I}, \mathrm{Mn}, \mathrm{Zn}$ e Se. Os primeiros 7 elementos são denominados de macroelementos, pois são necessários aos animais em quantidadesa maiores. Os últimos sete são denominados microelementos, oligoelementos ou elementos-traços, porque necessários aos 
animais em quantidades muito pequenas. Ultimamente temse acrescido mais alguns minerais à lista supramencionada, como o flúor, molibdênio, cromo, níquel, vanádio e silício.

A deficiência de cálcio ocorre em animais que se alimentam de concentrados, ricos em P, como suínos e aves, que além disto, são espécies que necessitam de mais Ca na dieta do que os bovinos. A deficiência de Ca, porém, pode ocorrer em bovinos que recebem alimentação abundante em concentrados; naqueles em regime de campo não constitui problema. Por mais pobres em Ca que sejam as pastagens, os bovinos sempre recebem quantidades suficientes de Ca através delas ou da forragem. Os fatores que contribuem para isto, são os seguintes: a) a maioria das plantas contém mais Ca do que $\mathrm{P}$, b) solos deficientes em Ca são menos comuns que os carentes em $\mathrm{P}$ e c) os níveis de Ca não diminuem com a maturação das plantas, como é o caso com o $P$.

Já a deficiência de fósforo é muito importante para bovinos, principalmente em relação àqueles mantidos em regime de campo. Extensas áreas com deficiência de $\mathrm{P}$ nas pastagens ocorrem em todo mundo e não há dúvida que essa deficiência é o distúrbio mineral mais comum e, também economicamente, mais importante afetando os herbívoros em regime de campo no Brasil.

A verdadeira deficiência de magnésio só ocorre em bezerros alimentados exclusivamente à base de leite, os chamados "bezerros de leite". O leite sabidamente é pobre em Mg e Fe. Nesse regime de alimentação, os bezerros ficam anêmicos em virtude da deficiência de Fe e tem a carne esbranquiçada - além disto sofrem as consequências da deficiência de $\mathrm{Mg}$, caracterizada por manifestações neuro-musculares. A tetania da lactação ou tetania hipomagnesêmica, perturbação metabólica que afeta sobretudo vacas em lactação, não é uma simples deficiência de $\mathrm{Mg}$, mas sim um processo mais complexo, na qual uma deficiência desse elemento na pastagem está envolvida.

Não há relatos sobre a deficiência de potássio em bovinos mantidos em regime natural de alimentação.

Já a deficiência de sódio é a carência mineral mais comum em todo mundo, além de ser a mais importante, depois da deficiência de P. Levantamentos têm demonstrado que o $\mathrm{Na}$ é deficiente nas pastagens em todos os continentes. Quando se fala na necessidade de administrar sal ao gado, isto significa fornecer o Na. Em relação ao cloro, de uma maneira geral, não há necessidade de suplementação ao gado, pois só raramente, e assim mesmo para vacas com alta produção de leite, este elemento contido na pastagem pode não ser suficiente para suprir as necessidades desses animais. Mas, como a suplementação de sódio se faz através do sal comum $(\mathrm{NaCl})$, não se justifica qualquer preocupação neste particular.

Não se conhece a deficiência de enxofre em bovinos mantidos em regime de pastagem.

A deficiência de ferro não ocorre em bovinos, a não ser nos "bezerros de leite", acima mencionados. A deficiência de ferro é observada em leitões criados em compartimentos com piso de cimento, isto é quando não têm acesso ao solo para se abastecerem deste elemento. $O$ solo e as pastagens são muito ricos em ferro.

Em todo mundo, e também no Brasil, o cobre e o cobalto são os dois microelementos que mais frequentemente estão envolvidos em estados carênciais nos bovinos. Em geral, as deficiências desses elementos determinam quadros clínicopatológicos relativamente característicos.

Mesmo antigamente, quando não se enriquecia o sal de cozinha com iodo e o bócio era comum no homem, essa deficiência era de rara ocorrência em bovinos em todo o mundo. Acredita-se que os bovinos necessitam de menores quantidades de iodo na alimentação do que o homem, ou então, que os alimentos ingeridos pelos bovinos nessas mesmas regiões onde ocorria o bócio no homem, forneciam suficiente iodo aos bovinos.

A deficiência de manganês é bem conhecida nas aves, nas quais é responsável pela perose e pela condrodistrofia nutricional. Trata-se de doenças caracterizadas por alterações esqueléticas. Somente em poucas instâncias, diagnósticos dessa deficiência mineral têm sido comunicados em bovinos; pelo menos em alguns casos esse estado carencial estava condicionado por excesso de outros elementos. Parece, especialmente no Brasil, que as pastagens contêm quantidades suficientes de manganês para suprir as necessidades desse elemento aos bovinos.

Acreditava-se que a deficiência de zinco era rara em bovinos. Conhecia-se bem a paraqueratose dos suínos, afecção determinada por deficiência de $\mathrm{Zn}$, em geral, condicionada por excesso de Ca na alimentação. Quadros de paraqueratose em bovinos são raros em todo mundo; hoje sabe-se, porém, que a deficiência de zinco ocorre em bovinos, de forma subclínica, em extensas regiões do mundo, inclusive no Brasil. Há descrição, também no Brasil, da chamada paraqueratose hereditária, distúrbio no qual fica prejudicada a absorção de zinco pela mucosa intestinal.

A deficiência de selênio é causa de diversos problemas em bovinos, principalmente da "doença do músculo branco" (distrofia muscular) e ainda de outros distúrbios, entre eles os relacionados à esfera reprodutiva. Essa deficiência é bem conhecida em muitos países, porém no Brasil, ainda sabemos pouco sobre sua ocorrência em nossos rebanhos.

Diagnóstico de deficiência mineral em bovinos em regime de campo

A indicação de medidas corretivas e profiláticas corretas passa pelo diagnóstico das deficiências minerais. Também no diagnóstico dessas deficiências, como no de qualquer problema, é necessário que se estudem as suas diversas manifestações e que se explore a questão sob diversos ângulos, para só então tirarem-se conclusões pelo exame do conjunto dos dados obtidos. O primeiro passo, importante, é o exame do rebanho: em grande parte das deficiências minerais mais acentuadas, o histórico, o exame clínico, a realização de necropsias e os estudos histopatológicos podem ajudar consideravelmente no estabelecimento do diagnóstico. Assim, a osteofagia, aliada ao raquitismo e à osteomálacia e a baixos índices de fertilidade, sugere deficiência de fósforo; a presença de bócio endêmico em bezerros indica deficiência de iodo; um histórico de que ruminantes não sobrevivem a não ser quando mudados periodicamente para "terras sadias", quando associa- 
do a sintomas de perda e perversão de apetite, emagrecimento e anemia progressiva, constitui um indício forte de deficiência de cobalto; hemossiderose acentuada em baço, linfonodos e, eventualmente, fígado, sugere deficiência de cobre; à ocorrência de paraqueratose, deve ser lembrada a deficiência de zinco, e à constatação de miopatias (distrofia muscular) é preciso ter-se em mente a possibilidade de que se trate de condição que responde a administração de selênio. Dados valiosos podem ser colhidos através dos exames microrradiográficos e histológicos de fragmentos de tecido ósseo (costela); com essa metodologia, ainda pouco explorada, consegue-se colher informações seguras, entre outras, sobre o desenvolvimento do esqueleto, face às disponibilidades de $\mathrm{P}$ e Ca durante o crescimento do animal (Dämmrich 1986, comunicação pessoal).

Porém na maioria das deficiências minerais e, em especial, quando não acentuadas, a determinação do quadro clínico-patológico, apesar de muito importante, não é suficiente. A certeza final no diagnóstico da maioria das deficiências minerais é dada por dois meios:

a) por dosagens químicas,

b) pela experimentação.

Em relação às dosagens químicas deve-se recorrer, em primeiro lugar, a análises de material proveniente de animais, e somente em segundo plano à análise de pastagens, e por último, à análise do solo.

A análise de material proveniente dos animais permite verificar, de forma direta, com maior rapidez e mais facilmente, as deficiências existentes, com menor risco de erros na interpretação dos resultados (Boyazoglu et al. 1972, Miller \& Stake 1974, Mendes 1977, Underwood 1981, Conrad 1984). Tratando-se de fígado e osso, com número relativamente pequeno de amostras pode-se chegar a conclusões bastante seguras sobre a ocorrência de deficiências minerais em extensas regiões.

A análise de amostras de fígado é eficaz para avaliar a condição do animal em relação a $\mathrm{Co}, \mathrm{Cu}, \mathrm{Mn}$ e Se e , eventualmente, a Zn. Mendes (1977), baseado em dosagens de amostras de fígado de mais que 500 bovinos que analisou para $\mathrm{Fe}$, $\mathrm{Cu}, \mathrm{Zn}, \mathrm{Mn}$, Co e Mo, concluiu que o nível de certos minerais no gado pode ser determinado satisfatoriamente em amostras de fígado obtidas, ou por biópsia, ou por abate, próximo ao fim da estação de chuvas, uma vez que esta é a época do ano em que os animais são mais produtivos e suas exigências são maiores. A análise de tecido ósseo é indicada em estudos sobre as deficiências de P e Ca. Análises de sangue, soro e plasma são úteis no diagnóstico de deficiências de $\mathrm{Mg}, \mathrm{Zn}$, $\mathrm{Cu}$, P e Ca, mas têm as suas limitações; por exemplo, os teores de $P$ são influenciados por estresse, exercício, hemólise, temperatura e tempo de separação do soro sanguíneo (Dayrell et al. 1973b). Para a determinação de certas deficiências minerais, ainda outros materiais provenientes do animal podem ser analisados, como pêlos (na deficiência de $\mathrm{Zn}$ ), saliva, urina e fezes (na deficiência de $\mathrm{Na}$ ).

Como a deficiência mineral no animal está ligada ao pasto e este, por sua vez, depende do solo, análises de pastagem e de solo, cobrindo determinadas regiões e finalmente todo o Brasil, têm sido advogadas; nesse sentido já foram realizados alguns levantamentos em determinadas regiões do país. Conclusões válidas através desse tipo de levantamento demandam elevados recursos humanos e materiais, são de execução bastante difícil e os resultados obtidos não são de fácil interpretação.

Em amostras de pastagens, os valores encontrados em relação a alguns elementos só têm valor relativo, pois devem ser confrontados com os de outros minerais da mesma amostra, que podem produzir interferência na sua assimilação pelo animal. Além disso, em muitas regiões, a coleta da amostra representativa de forragem, ou seja, daquilo que os animais ingerem, muitas vezes é impossível. Há ainda a considerar as variações dos teores dos elementos nas amostras da mesma pastagem nas diferentes épocas do ano, variações essas que, relativamente à maioria dos elementos, são bastante grandes (são muito maiores que no material proveniente do animal). Por isso, as amostras têm de ser coletadas em número elevado e vários minerais têm que ser analisados. Também devem ser levadas em consideração a quantidade do mineral que é assimilável pelo animal, a contaminação das amostras pelo solo e a circunstância de os animais ingerirem alguma quantidade de solo juntamente com a pastagem; no Piauí e no Maranhão, em certas regiões das chapadas, as fezes dos bovinos contêm quantidades muito elevadas de terra, a tal ponto que elas têm aspecto e consistência de cerâmica. A ingestão de solo, na Nova Zelândia, pode chegar a $600 \mathrm{~kg}$ por ano para vacas de leite (Healy 1974). Em ovinos, Healy \& Ludwig (1965) encontraram valores de até $3 \mathrm{lbs}(1,5 \mathrm{~kg})$ por semana/animal durante os meses úmidos de inverno, quando os pastos são curtos e lamacentos. Esses mesmos autores acham que valores próximos de $50 \mathrm{lbs}$ $(25 \mathrm{~kg})$ por ano podem ocorrer em certas fazendas e sugerem que o solo ingerido pode ser uma fonte importante de microelementos. Conrad (1984) pondera que a ingestão de grandes quantidades de solo pode diminuir a absorção de $\mathrm{P}$.

A interpretação dos resultados das análises do solo tornase ainda mais difícil em relação à maioria dos elementos, visto que, além de interferências, deve ser considerado que nem todas as quantidades de um mineral existentes no solo são aproveitáveis pelas plantas, por haver diversos fatores influenciando a sua assimilação, como, por exemplo, o pH do solo e a forma química do elemento no solo.

Deve-se ressalvar, porém, que análises de amostras de pastagem e de solo não são desprovidas de valor e, sim, constituem um complemento importante no estudo das deficiências minerais, como tem sido demonstrado pelos trabalhos de Mendes 1977, Mendes et al. (1981, 1982), Souza (1978), Souza et al. (1979, 1980, 1981, 1982, 1986, 1987, 1989), Souza \& Darsie (1985, 1986), Lopes et al. (1980a,b), Brum et al. (1987a,b) e Pott et al. (1987, 1989a,b,c,d,e). Queremos destacar o valor que têm as análises de Na na pastagem e de P no solo (Dayrell et al. 1973a).

Um outro recurso no diagnóstico das deficiências minerais é a experimentação. Consiste, basicamente, na administração do mineral que se suspeita deficiente a um grupo de 
animais, mantido em pastagem suspeita de ser carente. Outro grupo de animais deve ficar como testemunha, isto é, sem receber o mineral e mantido no mesmo regime de alimentação. $O$ principal parâmetro para avaliação dos resultados é a variação do peso dos animais durante a experimentação. Também outros parâmetros, como, por exemplo, o índice de fertilidade, podem ser utilizados (Conrad \& Mendes 1965, Grunert \& Santiago 1969, Guimarães \& Nascimento 1971). A experimentação é um excelente meio de diagnóstico no estudo das deficiências minerais. Infelizmente, é um método dispendioso, trabalhoso e demorado.

Em conclusão, quanto maior o número de dados, maior segurança há no diagnóstico. $\mathrm{O}$ procedimento mais correto e seguro no diagnóstico das deficiências minerais é o exame do rebanho, sob o ponto de vista clínico-patológico, complementado por análises químicas de tecido animal e/ou experimentação. Análises de pastagem, ou ainda análises de solo, sempre constituem apenas um complemento.

Esse procedimento é também importante com relação ao diagnóstico diferencial. Algumas suspeitas de deficiência mineral não são confirmadas. Queremos dar alguns exemplos:

Sutmöller et al. (1966), estudando mortes de evolução superaguda ("morte súbita") na Região Amazônica, que denominaram "malde-cai", concluíram que elas fossem causadas por um distúrbio mineral alimentar, decorrente da carência de sódio e potássio, associado a um desequilíbrio $\mathrm{Ca} / \mathrm{P} / \mathrm{Mg}$ no soro, caracterizado por valores séricos aumentados de magnésio, relativamente altos de fósforo e diminuídos de cálcio. Hoje sabemos que essas "mortes súbitas" nas regiões visitadas por esses autores (Baixo Amazonas, Amapá) são causadas por duas plantas: Palicourea marcgravii na "terra firme" e Arrabidaea bilabiata na "várzea" (Tokarnia et al. 1979).

Em outra ocasião foi levantada a suspeita de que as "mortes súbitas" que ocorrem na "Zona da Mata" em Pernambuco estariam ligadas à deficiência de cobre (Cavalcanti 1967, com. pessoal), como tem sido descrito na Austrália para a "falling disease" (Underwood 1981). Sabe-se, hoje, que essas mortes que ocorrem na "Zona da Mata” de Pernambuco também são causadas por uma planta, Palicourea aeneofusca (Tokarnia et al. 1983).

Um terceiro exemplo é o "espichamento" dos bovinos no pantanal de Mato Grosso, doença caracterizada por calcinose; suspeitavase de uma perturbação no metabolismo de $\mathrm{Ca} / \mathrm{Mg}$ inerente à composição do solo. Hoje sabemos que se trata de intoxicação pela planta calcinogênica Solanum malacoxylon (Döbereiner et al. 1971).

Por fim, queremos citar a "borrachera" na Venezuela, uma espécie da "falling disease"; de acordo com McDowell et al. (1983), os animais afetados têm valores de cobre muito baixos no fígado. Essa doença, porém, é causada pela planta tóxica Arrabidaea bilabiata (Cortes 1969/71).

Medidas corretivas e profiláticas nas deficiências minerais em bovinos

Uma vez estabelecido o diagnóstico de determinada(s) deficiência(s) mineral(ais) em um rebanho em uma região, há que se indicar as medidas corretivas e profiláticas apropriadas, que consistem basicamente no seguinte:

1) adubação do solo com o(s) elemento(s) deficiente(s) seria a medida ideal, pois além de resolver o problema da deficiência mineral no animal, em alguns casos também traz aumento da produção de massa verde e melhoramento da pastagem. Infelizmente é um método caro.
2) a administração do(s) elemento(s) deficiente(s) ao animal, seja por via oral, geralmente misturado(s) ao sal comum, ou, em condições especiais, através da água $(\mathrm{P})$, por meio de "balas" (Co), ou seja por via parenteral $(\mathrm{Cu})$.

Para ruminantes criados em regime de campo, tanto no Brasil, como em outros países, o método mais usado e indicado é a administração dos elementos deficientes com o sal comum, deixado em cochos, à vontade. A função do sal nestas misturas é de estimular, por um lado, ou de limitar, por outro, a quantidade dos elementos a ser ingerida.

Tem-se sugerido a administração de misturas minerais pretensamente "completas", acreditando-se que esta prática prescindiria todo o trabalho de diagnóstico acima descrito e evitaria quaisquer omissões. Seria o uso indiscriminado destas misturas minerais, de uma maneira geral, para todos os bovinos. Seria ótimo se este procedimento resolvesse e pudesse ser aplicado na prática. Mas, infelizmente, não funciona, pelas razões que se seguem.

1) É um método antieconômico: De início, pode-se perguntar, o que é uma mistura mineral "completa"? Essa designação é muito vaga. Por razões comerciais, a tendência é incluir o maior número possível de minerais nas misturas. A maioria dos criadores desavisados optará em adquirir o produto que encerrar o maior número de minerais . No seu julgamento, seria o melhor. De acordo com os nossos conhecimentos atuais, uma mistura mineral adequada para bovinos no Brasil, deveria conter somente $\mathrm{P}$, $\mathrm{Co}$, $\mathrm{Cu}$, I e $\mathrm{Zn}$, tendo como veículo o sal comum. Mas mesmo assim, a administração de todos esses elementos, a todos os bovinos no Brasil, seria um desperdício muito grande. Há regiões onde não ocorrem deficiências minerais, e onde ocorrem, na maioria das vezes, não envolvem todos os elementos. A suplementação mineral não é uma prática barata - sobretudo quando está envolvido o $\mathrm{P}$, cuja deficiência, infelizmente, é a mais comum e importante. Fornecer $\mathrm{P}$ adicional aos bovinos, acima das necessidades, é um desperdício. Por outro lado, se realmente ocorre a deficiência de $\mathbf{P}$ num rebanho ou numa região, é preciso avaliar bem a situação, e fazer-se uma suplementação adequada - o que já representa um investimento apreciável.

2) Porque há o perigo das interferências: É bem conhecida a ação prejudicial do excesso do Fe na alimentação sobre a absorção do $\mathrm{P}$ no trato digestivo, bem como as ações antagônicas do Mo sobre o $\mathrm{Cu}$, do $\mathrm{Mn}$ sobre o $\mathrm{Fe}$, do $\mathrm{Zn}$ sobre o Cu e do Ca sobre o Zn, para citar alguns exemplos. É preciso ter em mente esse aspecto, quando se pretende aperfeiçoar a alimentação dos animais pelo fornecimento de minerais adicionais.

Já que a suplementação "completa" é muito dispendiosa, o que se observa, é que a maioria dos criadores suplementa os seus rebanhos com estas ditas misturas "completas", porém em quantidades muito abaixo das recomendadas para corrigir deficiências minerais eventualmente existentes. Suplementar com essas misturas é, literalmente, jogar dinheiro fora. A esta observação recebemos, certa vez, como resposta, que a suplementação com uma mistura mineral "comple- 
ta" seria somente para se fornecer uma base; se realmente existe uma deficiência, seria necessário diagnosticá-la e suprir o rebanho com doses extras deste mineral.

Composição das misturas minerais

Um outro problema que deve ser aqui considerado, diz respeito à composição da mistura mineral. Há muita mistificação neste tópico. Há laboratórios que usam a seguinte propaganda junto ao criador: "Envie uma amostra de sua pastagem e nós, à base de análises químicas, lhe forneceremos uma mistura mineral específica para o seu rebanho." À parte da pretensão de se querer fazer o diagnóstico com base em uma única amostra de pastagem (vide diagnóstico das deficiências minerais), é uma ilusão querer, através de tais análises químicas, indicar as quantidades exatas dos diversos minerais a serem suplementados aos bovinos, fazenda por fazenda, rebanho por rebanho. A suplementação mineral se baseia no seguinte: verificar (diagnosticar), se há ou não a deficiência de um ou mais elementos no rebanho e, em caso positivo, suplementar o(s) mineral(ais) deficiente(s). As quantidades dos minerais que devem ser acrescidas são iguais em todo mundo, pois a suplementação mineral só pode ser feita em termos muito gerais. Caso se quisesse suplementar os minerais deficientes nas quantidades exatas aos nossos bovinos, o que é teoricamente possível, haveria que se subtrair das necessidades (requerimentos) aquilo que os animais obtém através da pastagem. Teriam que ser realizadas análises químicas de amostras representativas daquilo que os bovinos ingerem na pastagem, durante as diversas estações do ano, além de ser determinada a parte destes minerais assimilável (aproveitada) pelos bovinos, dadas as muitas interferências possíveis; faltaria, ainda, verificar qual a quantidade de solo ingerido junto com a pastagem. Isto deveria ser feito em relação a cada categoria de bovinos, como bovinos em crescimento, vacas secas, vacas em lactação e bois de engorda. Ao final teríamos um número apreciável de misturas minerais para cada fazenda e mesmo assim sem garantia de uma suplementação perfeita, pois nem todos os bovinos ingerem por igual, individualmente e durante o ano, os $30 \mathrm{~g}$ de sal por dia, que é a média mundial e que serve como base para as formulações de misturas minerais.

Com base em cálculos e na experimentação, realizados principalmente na África do Sul e na Austrália, chegou-se a conclusão que o melhor que se pode fazer em termos de suplementação mineral em bovinos em regime de campo, é usar as seguintes proporções dos diversos minerais em relação ao sal comum, sempre lembrando que só deve ser supementado o mineral deficiente ou pelo menos suspeito de ser deficiente:

$\begin{array}{ll}\text { Sal comum }(\mathrm{NaCl}) & 50 \mathrm{~kg} \\ \text { Fosfato bicálcico }\left(\mathrm{CaHPO}_{4}\right) & \begin{array}{l}50 \mathrm{~kg} \text { [ou } 100 \mathrm{~kg} \text { de fa- } \\ \text { rinha de osso] }\end{array} \\ \begin{array}{l}250 \mathrm{~g} \\ \text { Sulfato de cobre }\left(\mathrm{CuSO}_{4}\right)\end{array} & 30 \text { a } 60 \mathrm{~g} \\ \text { Sulfato ou cloreto de cobalto }\left(\mathrm{CoSO}_{4} \text { ou CoCl }_{2}\right) & 250 \text { a } 500 \mathrm{~g} \text { [ou } 125 \text { a } \\ \text { Sulfato de zinco }\left(\mathrm{ZnSO}_{4}\right) & 250 \mathrm{~g} \mathrm{de} \text { óxido de zin- } \\ & \text { co }(\mathrm{ZnO})]\end{array}$

Selenito de sódio $\left(\mathrm{Na}_{2} \mathrm{SeO}_{3}\right)$

Iodato de potássio $\left(\mathrm{KIO}_{3}\right)$

Sulfato de manganês $\left(\mathrm{MnSO}_{4}\right)$
8 a $18 \mathrm{~g}$

1,7 a 8,0 g Igeralmen-

te o sal já vem iodado]

250 a $500 \mathrm{~g}$

Veremos, de forma sucinta, como se determinaram as proporções dos diversos minerais na fórmula acima indicada.

Sabe-se que, em quase todas as regiões do mundo os bovinos consomem sal voluntariamente, na média de $30 \mathrm{~g}$ de sal por cabeça/dia. $O$ princípio básico na formulação da mistura mineral é acrescentar a esta quantidade de sal comum, as quantidades dos diversos minerais a serem suplementados. O sal serve, por um lado, como estimulante para que o bovino ingira os outros minerais e, por outro, como "freio" para que não haja consumo além do previsto.

Em relação ao fósforo, com base nas exigências nutricionais dos bovinos e em extensa experimentação, chegou-se aos valores acima indicados da seguinte maneira. Sabe-se que bovinos em crescimento precisam de 12 a $20 \mathrm{~g}$ de P por cabeça/dia. Através da experimentação verificou-se que a suplementação de $6 \mathrm{~g}$ de $\mathrm{P} /$ dia por animal é suficiente para evitar os efeitos negativos da deficiência de P. Também através de experimentos, verificou-se que não tem valor suplementar com fósforo na época de seca, quando os pastos são mais carentes neste elemento, pois nessa época a deficiência de $\mathbf{P}$ não constitui o fator limitante na alimentação dos bovinos. Seis gramas de fósforo correspondem a $60 \mathrm{~g}$ de farinha de osso, que por sua vez correspondem a $30 \mathrm{~g}$ de fosfato bicálcico (sempre na base de cálculos e na experimentação). Concluise que a farinha de osso deve ser oferecida ao dobro e o fosfato bicálcico na mesma quantidade de sal. Um aspecto que deve ser aqui lembrado, é que o bovino, ao contrário do homem, do suíno e de outras espécies, é muito tolerante à relação cálcio:fósforo, que nesta espécie pode variar de 6:1 a $0,6: 1$, desde que os dois minerais estejam presentes em quantidades suficientes na alimentação.

Em relação ao cobre, o valor acima indicado foi obtido da seguinte forma. Os bovinos necessitam de $100 \mathrm{mg}$ de cobre por cabeça/dia, o que corresponde a $400 \mathrm{mg}$ de sulfato de cobre, composto geralmente usado na suplementação de cobre aos animais. Se nos pretendemos suplementar metade das necessidades de cobre, seriam necessários $200 \mathrm{mg}$ de sulfato de cobre por cabeça/dia. Se $50 \mathrm{~kg}$ de sal $(\mathrm{NaCl})$ é a quantidade que 1666 bovinos consomem em um dia (50.000 g divididos por $30 \mathrm{~g}$ ), temos que multiplicar $200 \mathrm{mg}$ por 1666 , donde obtém-se a quantidade de $333.200 \mathrm{mg}$, que corresponde a $333 \mathrm{~g}$ de sulfato de cobre a ser adicionada a $50 \mathrm{~kg}$ de sal. Como a ingestão excessiva de cobre acarreta sua acumulação no organismo e pode causar intoxicação letal (os ovinos são especialmente sensível a este problema), a tendência é não exagerar e, em geral, recomendam-se $250 \mathrm{~g}$ de sulfato de cobre para cada $50 \mathrm{~kg}$ de sal.

Em relação ao cobalto é aconselhado administrar aos bovinos de 5 a $10 \mathrm{mg}$ de cobalto por cabeça/dia, o que corresponde a $20 / 40 \mathrm{mg}$ de sulfato ou cloreto de cobalto. Para suplementar a quantidade de $5 \mathrm{mg} /$ cabeça/dia, seguindo o mesmo raciocínio usado para o cobre, temos que multiplicar 20 
por 1666 e obteremos a quantidade de $33.320 \mathrm{mg}$, o que corresponde a $33 \mathrm{~g}$ ou, arredondado, $30 \mathrm{~g}$ de sulfato ou cloreto de cobalto a ser adicionado a $50 \mathrm{~kg}$ de sal.

No que se refere ao zinco, temos, de forma análoga, que acrescentar $250 \mathrm{~g}$ a $500 \mathrm{~g}$ de sulfato de zinco a $50 \mathrm{~kg}$ de sal, ou a metade quando se usa óxido de zinco.

Em relação ao selênio recomenda-se a administração de 2 a $5 \mathrm{mg}$ de Se por cabeça/dia, o que corresponde a 4,4 a $11 \mathrm{mg}$ de selenito de sódio. Para suplementar a quantidade de 4,4 $\mathrm{mg} / \mathrm{dia}$, temos que muliplicar 4,4 por 1666 e obteremos a quantidade de $7.330 \mathrm{mg}$, o que corresponde, arredondado, a $8 \mathrm{~g}$ de selenito de sódio a ser adicionados a $50 \mathrm{~kg}$ de sal.

Não há necessidade de fornecer iodo ao gado, pois o nosso sal já vem iodado; se for suplementado, deve ser sob a forma de iodato.

O manganês, se for suplementado, o deve ser sob a forma de sulfato de manganês, na mesma quantidade que o sulfato de zinco.

Deve ser lembrado que os bovinos não precisam ser suplementados com minerais em todas as regiões do Brasil, com exceção do sal comum. $O$ gado deve receber sempre $o$ sal comum, mas outros elementos apenas quando a sua deficiência foi diagnosticada na região, ou quando, pelo menos, haja suspeitas neste sentido. Não seguir esta regra básica e querer dar misturas minerais "completas" para todos os bovinos, acarreta gastos desnecessários e, às vezes, pode até causar problemas (por exemplo, numa região onde a pastagem é pobre em molibdênio, a administração de cobre pode provocar, especialmente em ovinos, intoxicação por este último elemento; a administração de ferro, por prejudicar a absorção do fósforo no trato digestivo, pode provocar ou agravar as manifestações da deficiência de fósforo no rebanho). Por outro lado, muitas vezes, devido aos altos custos de misturas minerais idôneas e consequente tendência da suplementação em quantidades menores que as indicadas, não se resolve o problema, quando este realmente existe, principalmente quando está envolvida a deficiência de fósforo. A correção da deficiência de $P$ é cara, pois as quantidades deste macroelemento, a serem suplementadas, são grandes.

Ultimamente, o enfoque dado aos minerais em relação a saúde e produtividade dos rebanhos bovinos tem sido, principalmente por parte de nutricionistas, diferente, especialmente em relação aos rebanhos de alta produtividade. Aí não se fala mais em deficiências minerais e como corrigí-las, mas na inclusão das mais diversas substâncias, inclusive minerais, para aumentar a sua produtividade, para dar o "algo mais"; fala-se aí em aditivos. Acreditamos que esta tendência tem surgido em virtude dos conhecimentos cada vez maiores dos muitos processos bioquímicos que ocorrem no organismo animal. Sabendo-se por exemplo que o $\mathrm{Zn}$ entra na composição de diversas metalo-enzimas, que tem diversas funções estratégicas no organismo, pode-se entender a preocupação de não deixar faltar de maneira alguma na alimentação dos bovinos este mineral.

A melhor maneira e, talvez única, de os veterinários, zootecnistas e criadores avaliarem até que ponto a inclusão deste ou aquele aditivo na alimentação é de valor, é através da experimentação. $\mathrm{O}$ alerta sobre a inconveniência das "misturas completas" continua válido também para os aditivos.

\section{BREVE HISTÓRICO SOBRE OS ESTUDOS DAS DEFICIÊNCIAS MINERAIS EM BOVINOS REALIZADOS NO BRASIL}

Os primeiros estudos sobre deficiências minerais em bovinos, no Brasil, se referem à deficiência de $\mathrm{P}$ e foram realizados na década de 40, no Estado de Minas Gerais. Gióvine (1943) fez o diagnóstico clínico da deficiência de P em bovinos, que foi complementado por Menicucci (1943) com dosagens de $\mathrm{P}$ em amostras de sangue. A deficiência de Co foi diagnosticada, no Brasil, pela primeira vez no Estado de São Paulo, por Correa $(1955,1957)$ ao estudar uma doença em bovinos conhecida vulgarmente pelos nomes de "peste de secar", "sablose", "mal de areia", "mal das cabeceiras" e "mal de colete". A deficiência de $\mathrm{Cu}$ foi diagnosticada, no Brasil, pela primeira vez, em bovinos no Estada do Piauí, em bovinos como causa de mau estado nutricional (Tokarnia et al. 1960) e, em ovinos, como responsável pela ataxia enzoótica, o "escancho" (Tokarnia et al. 1966). A deficiência de iodo, sob a forma do bócio congênito em bezerros, foi mencionada, pela primeira vez por Megale (1949), no oeste e sul de Minas Gerais.

Em seguida a esses trabalhos pioneiros no Brasil, foram realizados numerosos estudos sobre deficiências minerais no país. Predominavam inicialmente os trabalhos realizados sob a perspectiva do patologista, isto é, estudavam-se sobretudo doenças de etiologia obscura possívelmente causadas por deficiências minerais, isto é, estados carenciais mais acentuados.

Até 1976 haviam sido diagnosticadas as deficiências de $P$, $\mathrm{Co}, \mathrm{Cu}$ e I em bovinos em regime de campo. Já ficara bem estabelecido que a deficiência de $\mathrm{P}$ era, destacadamente, a mais importante, mas que as deficiências de Cu e Co também ocorriam em amplas áreas, sendo a de iodo limitada a algumas poucas regiões do Brasil. Secundariamente à deficiência de $\mathrm{P}$ foi diagnosticado o botulismo epizoótico no Piauí, no sul do Maranhão e norte de Goiás. Deficiências minerais, que se sabia ocorrerem em outros países, como as de $\mathrm{Zn}$, Mn e $\mathrm{Se}$, bem como as de $\mathrm{Na}$ e $\mathrm{Mg}$, não tinham sido diagnosticadas.

Um resumo sobre essas ocorrências diagnosticadas no Brasil até 1976, com as respectivas referências, constam de nossa revisão apresentada no Simpósio Latino-Americano sobre Pesquisa em Nutrição Mineral de Ruminantes em Pastagens, Belo Horizonte, 1976 (Tokarnia \& Döbereiner 1976, 1978). Vide Figura 1.

A partir dos meados da década de 70 , com a modificação que se fez nas pesquisas no campo da agropecuária através da criação da Embrapa, esta, ciente da grande importância das deficiências minerais como um dos entraves ao desenvolvimento da nossa pecuária, decidiu dar continuidade aos projetos de pesquisa sobre deficiências minerais em bovinos, mas de uma maneira mais abrangente, sob a perspectiva nutricional. A intenção era, através de levantamentos, que 


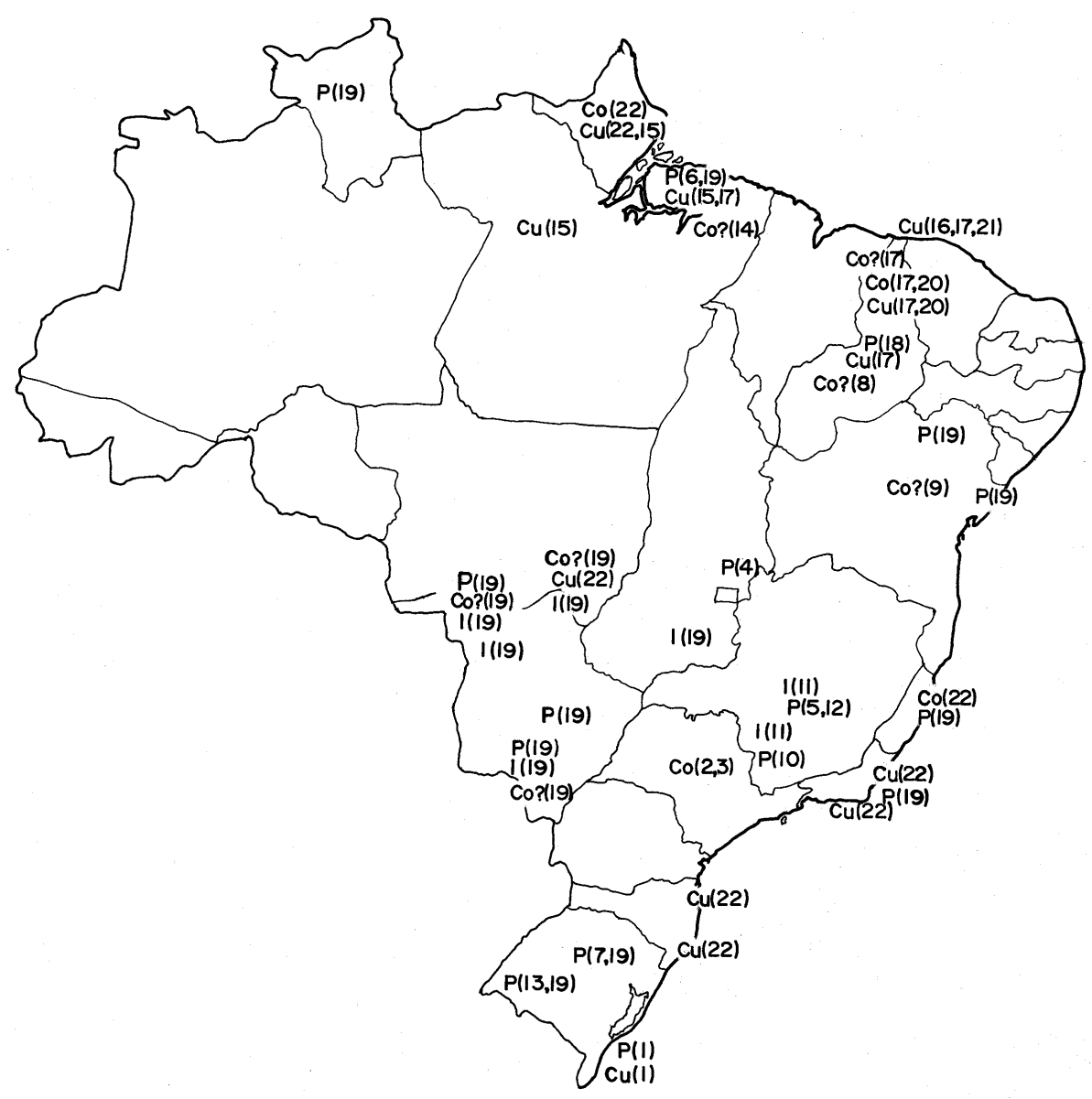

Fig.1. Deficiências minerais diagnosticadas no Brasil até 1976. Os números em parênteses indicam a fonte de informação obtida da seguinte literatura:

(l) Bauer A.C., Santos A.G. \& Mancuso P.C. 1964. Algumas observações sobre uma doença de bovinos no município de Santa Vitória do Palmar. III Conf.Soc.Vet.Rio Grande do Sul, Porto Alegre, p.153-161. - (2) Corrêa R. 1955. Carência de cobalto em bovinos no Estado de São Paulo. Revta Bras.Biologia 15:309-313. - (3) Corrêa R. 1957. Carência de cobalto em bovinos. Arqs Inst.Biológico, S.Paulo, 24:199-227. - (4) Dayrell M.S., Döbereiner J. \& Tokarnia C.H. 1973. Deficiência de fósforo em bovinos na região de Brasília. Pesq.Agropec.Bras., Sér.Vet.8:105114. - (5) Gióvine N. 1943. Estudo clínico da deficiência de fósforo nos bovinos de Minas Gerais. Arqs Esc.Vet., Belo Horizonte, 1:17-25, 7 fig. - (6) Guimarães J.M.A.B. \& Nascimento C.N.B. 1971. Efeito da suplementação mineral sobre a percentagem de nascimentos de bezerros em rebanhos de bovinos de corte na Ilha de Marajó. Série: Estudos sobre Bovinos, IPEAN, Belém, Pará, vol.1(no.2), p.37-51. - (7) Grunert E. \& Santiago C. 1969. Über den Einfluss von Knochenfuttermehl auf die Fruchtbarkeit von Fleischrindern in Rio Grande do Sul, Brasilien. Zuchthyg.4:65-71. - (8) Iglesias F.A. 1951. Caatingas e chapadões. Sér. 5a. Brasiliana, vol.271. Biblioteca Pedagógica Brasileira, Editora Nacional, São Paulo, p.357-363. - (9) Macedo J.N. 1952. Fazendas de gado no vale de São Francisco. Documentário da Vida Rural no.3, SIA, Min.Agricultura, Rio de Janeiro. - (10) Megale F. 1949a. Sobre a incidência de esterilidade em vacas no Estado de Minas Gerais. Arqs Esc.Vet., Belo Horizonte, 2:17-27. - (11) Megale F. 1949b. Contribuição ao estudo do bócio congênito nos bezerros, no Estado de Minas Gerais. Arqs Esc.Vet., Belo Horizonte, 2:143-150. - (12) Menicucci Sobrinho L. 1943. Carência de fósforo e cálcio nos bovinos. Arqs Esc.Vet., Belo Horizonte, 1:9-15. - (13) Santos V.T. \& Pereira Neto E. 1963. II Reunião de Zootecnia e Veterinária, Bagé, Rio Grande do Sul, p.63. - (14) Soares L.C. 1963. Guia de Excursão no.8, realizada por ocasião do XVIII Congr.Int.Geogr., Conselho Nacional de Geografia, Rio de Janeiro, p.304. - (15) Sutmöller P., Abreu A.V., Grift J.van der \& Sombroek W.G. 1966. Mineral imbalances in cattle in the Amazon valley. Communication no.53, Dep.Agric.Res., Amsterdam. 135 p. + tables. - (16) Tokarnia C.H., Canella C.F.C. \& Döbereiner J. 1960. Deficiência de cobre em bovinos no delta do Rio Parnaíba, nos Estados do Piauí e Maranhão. Arqs Inst.Biol.Animal, Rio de J., 3:25-37. - (17) Tokarnia C.H., Canella C.F.C., Guimarães J.A. \& Döbereiner J. 1968. Deficiências de cobre e cobalto em bovinos e ovinos no Nordeste e Norte do Brasil. Pesq.Agropec.Bras.3:351360. - (18) Tokarnia C.H., Canella C.F.C., Guimarães J.A., Döbereiner J. \& Langenegger J. 1970. Deficiência de fósforo em bovinos no Piauí. Pesq.Agropec.Bras.5:483-494. - (19) Tokarnia C.H. \& Döbereiner J. 1978. Observações próprias, em: Diseases caused by mineral deficiencies in cattle raised under range conditions in Brazil, p.163-169. In: Conrad J.H. \& McDowell L.R. (ed.) Latin American Symposium on Mineral Nutrition Research with Grazing Ruminants, Belo Horizonte, Brazil. - (20) Tokarnia C.H., Döbereiner J., Canella C.F.C. \& Dâmaso M.N.R. 1961. Deficiência de cobalto em bovinos na Serra da Ibiapaba, no Estado do Ceará. Arqs Inst.Biol.Animal, Rio de J., 4:195-202. - (21) Tokarnia C.H., Döbereiner J., Canella C.F.C. \& Guimarães J.A. 1966. Ataxia enzoótica em cordeiros na costa do Piaú. Pesq.Agropec.Bras.1:357-382. - (22) Tokarnia C.H., Guimarães J.A., Canella C.F.C. \& Döbereiner J. 1971. Deficiência de cobre e cobalto em bovinos e ovinos em algumas regiões do Brasil. Pesq.Agropec.Bras., Sér.Vet.6:61-77. 
iriam abranger todo o Brasil, diagnosticar também as subdeficiências minerais. Este propósito prevaleceu num período que se estendeu até quase o final da década de 80 .

Através de levantamentos em algumas áreas, principalmente nas Regiões Centro-Oeste e Norte, realizados ou patrocinados pela Embrapa, obteve-se, com base em análises químicas de tecidos animais, amostras de pastagem e solo, e também através de alguns trabalhos experimentais, dados importantes. Confirmou-se, através desses estudos e de alguns realizados por outras entidades, o que tinha sido visto até 1976, de que a deficiência de $P$ é a deficiência mais importante em bovinos no Brasil. O botulismo epizoótico nesse período foi diagnosticado também em muitas outras regiões do Brasil, praticamente em todas em que há deficiência de $\mathrm{P}$. Confirmou-se que as deficiências de Cu e Co eram, depois da deficiência de $\mathrm{P}$, as mais comuns no Brasil. Ratificou-se a presença, com dados concretos, através da experimentação em bovinos, a deficiência de $\mathrm{Na}$ (Souza et al. 1985), que se suspeitava ser de ocorrência muito comum no Brasil; seria provavelmente ainda mais comum que as deficiências de $\mathrm{Cu}$ e Co. Também pela primeira vez foi diagnosticada a deficiência de $\mathrm{Zn}$ (Souza et al. 1982), com base na análise do elemento no fígado e na experimentação, com indicações que esta deficiência não seria tão rara no Brasil, como se supunha, ao contrário, tudo indicando ser frequente, sob forma sub-clínica. A deficiência de Mn ocorreria somente em condições especiais. Os baixos valores desse elemento no fígado de bovinos encontrados em algumas fazendas da Região CentroOeste, foram atribuídos às altas concentrações de Fe nas forrageiras e à elevada suplementação mineral com Co, o que provocaria problemas na absorção e utilização do Mn (Mendes 1977, Souza et al. 1981). Nos estudos realizados ou patrocinados pela Embrapa, não foi incluído o Se. Até 1987 os únicos dados sobre a possível ocorrência de deficiência de Se foram os obtidos em análises químicas de amostras de fígado de bovinos, baixos em numerosas amostras procedentes de Mato Grosso e Mato Grosso do Sul (Moraes 1986) e em amostras de sangue de vacas de leite do Estado de São Paulo, com valores baixos na sua maioria (78\%) (Lucci et al 1984a).

Um resumo sobre as ocorrências diagnosticadas no Brasil entre 1976 e 1987, consta em nossa revisão apresentada na Reunião sobre Determinação de Carências e Suplementação Mineral em Bovinos, realizada em junho de 1987 em Campo Grande, Mato Grosso do Sul (Tokarnia et al. 1988). Vide Figura 2.

O projeto original da Embrapa foi muito ambicioso. Viuse com o passar do tempo que um levantamento nos moldes planejados iria absorver recursos elevados demais. Pelos dados disponíveis, em princípio, sabia-se o que ocorre em termos de deficiências minerais no Brasil. Não haveria necessidade e não se justificaria, através de um levantamento deste tipo, caríssimo, querer-se estabelecer o status mineral em todos os rebanhos do Brasil.

Também se verificou que as análises químicas, apesar de muito úteis, não são ideais para o diagnóstico das deficiências minerais, ainda mais pela suplementação mineral indiscriminada, cada vez mais intensiva, de nossos rebanhos.
Tem-se chegado à conclusão que é preciso recorrer, cada vez mais, a experimentação, que permite conclusões mais seguras e corretas.

Depois deste período de levantamentos, o enfoque dado pela Embrapa se dirigiu a um outro ponto importante dentro do campo das deficiências minerais. Uma vez estabelecidas a importância e a extensão das diversas deficiências minerais em bovinos no Brasil, o problema que mereceu a maior atenção foi o da correção das deficiências minerais, isto é, a suplementação mineral aos nossos rebanhos. A suplementação dos microelementos não oferece maiores dificuldades e é relativamente barato. Porém, a de P é o grande problema, principalmente pelos seus elevados custos. Para baixar esses custos, surgiu a idéia de se estudar a possibilidade do uso de nossos fosfatos de rocha (Rosa \& Cardoso 1987, Rosa 1989). Neste último período, isto é, a partir do final da década de 80, a Embrapa realizou ou patrocinou numerosos estudos sobre a disponibilidade do $P$ nesta fonte, bem como sobre o perigo da intoxicação pelo flúor ou metais pesados. Um levantamento bibliográfico desses trabalhos com uma conclusão técnica foi realizada pelo Departamento de Zootecnia da Faculdade de Agronomia da Universidade Federal do Rio Grande do Sul (Kessler et al. 1995) e também está sendo elaborado pelo colega Ivan Valadão Rosa, ex-pesquisador da Embrapa-Centro Nacional de Pesquisa de Gado de Corte, Campo Grande, Mato Grosso do Sul.

Naturalmente, nesse último período, teve continuidade a realização de estudos sobre a ocorrência de deficiências minerais em bovinos no Brasil, tanto através de análises químicas de amostras de tecidos animais, de amostras de pastagem e de solo, como pela experimentação, se bem que em escala menor do que nos períodos anteriores.

Confirmou-se a situação antes já verificada. Co e $\mathrm{Cu}$ são as deficiências de microelementos mais frequentes. A deficiência de $\mathrm{Zn}$ tem sido verificada com bastante frequência. A deficiência de Mn foi constatada raramente; ao conrário, em relação a este elemento, houve verificações de valores elevados com perigo de toxidez (Brum et al. 1987a,b, Pott et al. 1987, 1989a,b,c,d,e). Também se destacam os valores elevados de Fe em diversas regiões, permitindo presumir a ocorrência de toxidez deste mineral para bovinos ( Fichtner et al. 1987, Brum et al. etc.). Em relação ao Se, os dados continuam escassos, insuficientes para se saber qual a importância da ocorrência da deficência desse elemento em bovinos e ovinos no Brasil. A miopatia nutricional em bezerros foi diagnosticada uma única vez (Barros et al. 1988). Foram comunicadas diversas ocorrências de intoxicação por cobre em ovinos. Em relação aos macroelementos, poucos estudos foram realizados neste último período, destacando-se os sobre a ocorrência da deficiência de $\mathrm{P}$, que já pelos estudos anteriores foi vista ser a deficiência mineral mais importante no Brasil.

Entre os estudos realizados neste último período devem ser mencionados os sobre o "ronca", doença crônica em bovinos adultos caracterizada por respiração ruidosa, de etiologia ainda não esclarecida. Ela tem sido observada nos Estados do Piauí, Rio de Janeiro e Mato Grosso do Sul. Nesta 


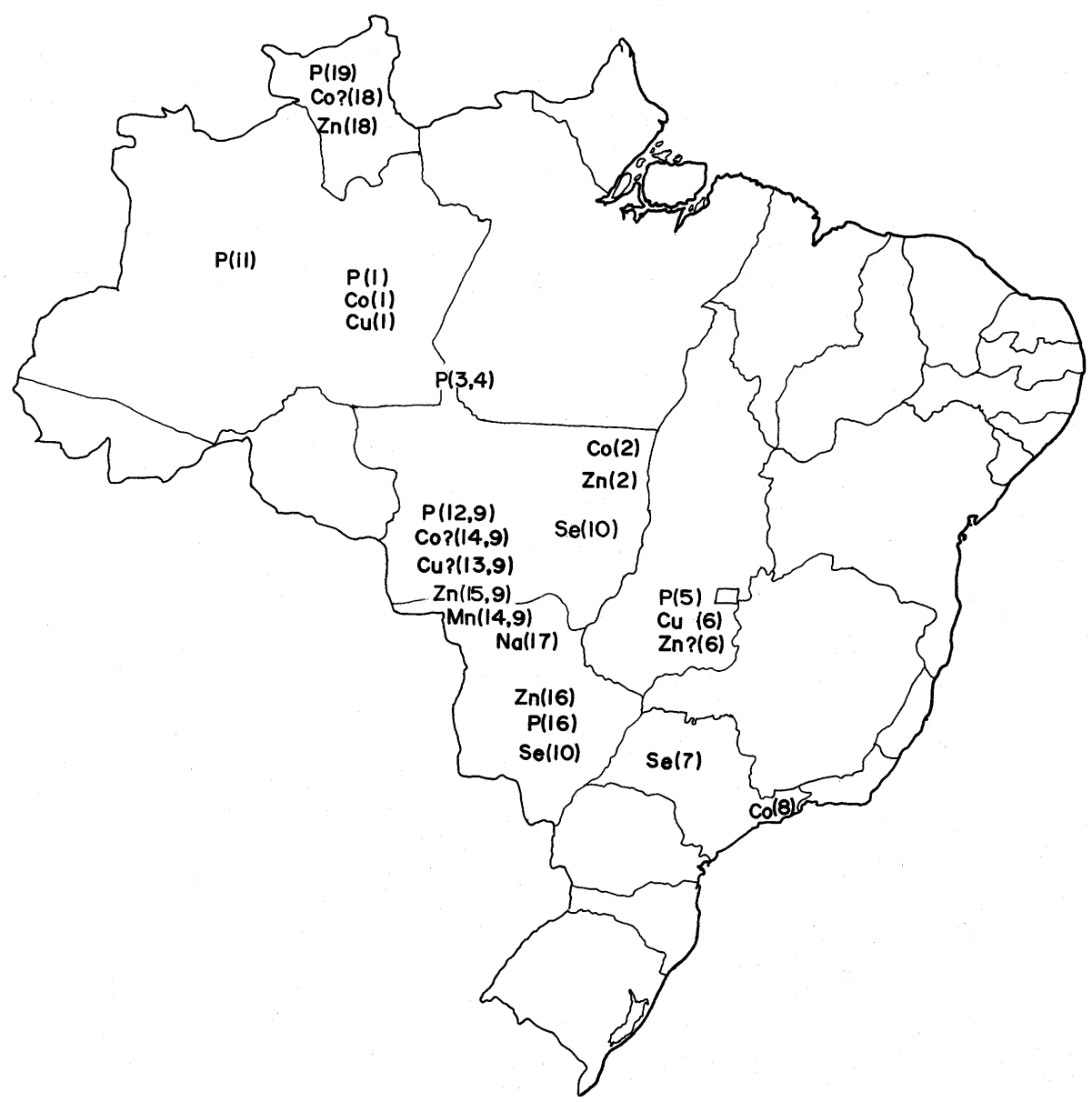

Fig.2. Deficiências minerais diagnosticadas no Brasil de 1976 a 1987. Os números em parênteses indicam a fonte da informação obtida da seguinte literatura:

(1) Barros N.N., Teixeira L.B., Moraes E., Canto A.C. \& Italiano E.C. 1981. Teores de minerais no complexo solo-planta-animal de áreas de terras firmes do Amazonas. Comunicado Técnico no.I6/81, Embrapa-UEPAE de Manaus. 3 p. - (2) Camargo W.V.A., Fernandes N.S. \& Santiago A.M.H. 1976. Pesquisa de minerais em bovinos no nordeste de Mato Grosso. Anais XV Congr.Bras.Med.Vet., Rio de Janeiro, p.194-195. Resumo. - (3) Camargo W.V.A., Fernandes N.S. \& Santiago A.M.H. 1980. Estudos de elementos minerais de interesse pecuário em regiões da Amazônia Legal. Arqs Inst.Bilógico, S.Paulo, 47(4):83-111. - (4) Camargo W.V.A., Santiago A.M.H., Nazário W. \& Chiba S. 1985. Teores de minerais de interesse pecuário em regiões da Polamazônia. Revta Bras.Med.Vet., Rio de J., 7(4):118-124. - (5) Fernandes N.S., Santiago A.M.H., Camargo W.V.A. \& Vianna S.S.S. 1976. Níveis estacionais de cobre e de cobalto em tecido animal e vegetal. Atualidades Veterinárias, Porto Alegre, 5(28):24-27. - (6) Lopes H.O.S., Fichtner S.S., Jardim E.C., Costa C.P. \& Martins Jr W. 1980a. Composição mineral de amostras de solo, forragem e tecido animal da microregião Mato Grosso de Goiás. I. Cálcio, fósforo, magnésio e potássio. Arqs Esc.Vet. UFMG, Belo Horizonte, 32(2):161-174. - (7) Lopes H.O.S., Fichtner S.S., Jardim E.C., Costa C.P. \& Martins Jr W. 1980b. Teores de cobre e zinco em amostras de solos, forrageiras e tecido animal da microregião Matro Grosso de Goiás. Arqs Esc.Vet.UFMG, Belo Horizonte, 32(2):151-159. - (8) Lucci C.S., Moxon A.L., Zanetti M.A., Schalch E., Pettinati R.L., Fukushima R.S., Franzolin Neto R. \& Marcomini D.G. 1983. Selênio em rebanhos leiteiros do Estado de São Paulo. I. Níveis de selênio em soros sangúneos - nota prévia. Anais XX Reunião Anual da SBZ, Pelotas, RS, p.197. - (9) Mendes M.O. 1977. Mineral status of beef cattle in the northern part of Mato Grosso, Brazil, as indicated by age, season, and sampling technique. Dissertation, University of Florida, Gainesville. 236 p. - (10) Moraes S.S. 1986. Untersuchungen zu Abhängigkeiten der Zink-, Mangan- und Selengehalte in Lebern von Rindern aus ausgewählten Regionen Brasiliens. Dissertation, Hannover. 146 p. - (11) Moraes E., Italiano E.C. \& Pieniz L.C. 1982. Efeito de níveis de fósforo no crescimento e engorda de bovinos mantidos em pastagem de quicuio da Amazônia. Pesquisa em Andamento no.36, Embrapa, UEPAE de Manaus. 4 p. - (12) Souza J.C., Conrad J.H., Blue W.G. \& McDowell L.R. 1979. Inter-relações entre minerais no solo, plantas forrageiras e tecido animal. 1. Cálcio e fósforo. Pesq.Agropec.Bras. 14(4):387-395. - (13) Sousa J.C., Conrad J.H., McDowell L.R., Ammerman C.B. \& Blue W.G. 1980. Inter-relações entre minerais no solo, forrageiras e tecido animal. 2. Cobre e molibdênio. Pesq.Agropec.Bras. 15(3):335-341. - (14) Sousa J.C., Conrad J.H., Blue W.G., Ammerman C.B. \& McDowell L.R. 1981. Inter-relações entre minerais no solo, forrageiras e tecido animal. 3. Manganês, ferro e cobalto. Pesq.Agropec.Bras. 16(5):739-746. - (15) Sousa J.C., Conrad J.H., Mott G.O., McDowell L.R., Ammerman C.B. \& Blue W.G. 1982. Inter-relações entre minerais no solo, plantas forrageiras e tecido animal no norte de Mato Grosso. 4. Zinco, magnésio, sódio e potássio. Pesq.Agropec.Bras. 17(1):1120. - (16) Sousa J.C., Gomes R.F.C., Rezende A.M., Rosa I.V., Cardoso E.G., Gomes A., Costa F.P., Oliveira A.R., Coelho Neto L. \& Curvo J.B.E. 1983. Resposta de novilhos nelorados à suplementação mineral em pastagens de capim-colonião. Pesq.Agropec.Bras. 18(3):311-318. - (17) Sousa J.C., Gomes R.F.C., Silva J.M.S. \& Euclides V.P.B. 1985. Suplementação mineral de novilhos de corte em pastagens adubadas de capim-colonião. Pesq.Agropec.Bras. 20(2):259-269. - (18) Sousa J.C. \& Darsie G. 1985. Deficiências minerais em bovinos de Roraima, Brasil. I. Zinco e cobalto. Pesq.Agropec.Bras. 20(11):1309-1316. - (19) Sousa J.C., Gonçalves E.M., Viana J.A.C. \& Darsie G. 1986. Deficiências minerais em bovinos de Roraima, Brasil. III. Cálcio e fósforo. Pesq.Agropec.Bras. 21(12):1327-1336. 


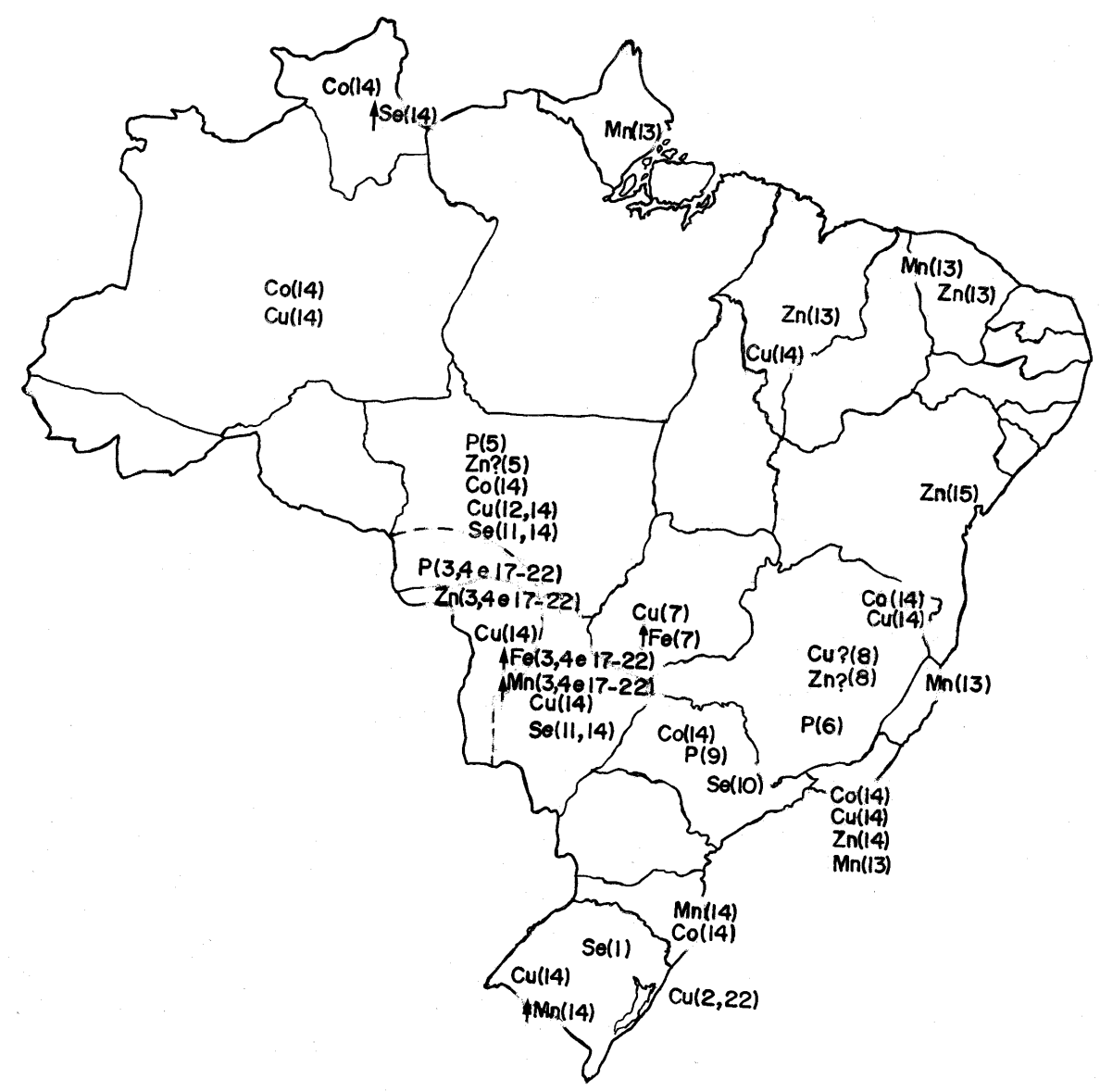

Fig. 3. Deficiências e desequilíbrios minerais em bovinos e ovinos diagnosticados no Brasil de 1987 a 1998 . Os números em parênteses indicam a fonte da informação obtida da seguinte literatura:

(1) Barros C.S.L., Barros S.S., Santos M.N. \& Metzdorf L.L. 1988. Miopatia nutricional em bovinos no Rio Grande do Sul. Pesq.Vet.Bras.8(3/ 4):51-55. - (2) Bondan E.F., Riet-Correa F. \& Giesta S.M. 1991. Níveis de cobre em fígados de bovinos no sul do Rio Grande do Sul. Pesq.Vet. Bras.11(3/4):75-80. - (3) Brum P.A.R., Sousa J.C., Comastri Filho J.A. \& Almeida I.L. 1987a. Deficiências minerais de bovinos na sub-região dos Paiaguás, no Pantanal Mato-grossense. I. Cálcio, fósforo e magnésio. Pesq.Agropec.Bras.22(9/10):1039-1048. - (4) Brum P.A.R., Sousa J.C., Comastri Filho J.A. \& Almeida I.L. 1987b. Deficiências minerais de bovinos na sub-região dos Paiaguás, no Pantanal Mato-grossense. II. Cobre, zinco, manganês e ferro. Pesq.Agropec.Bras. 22(9/10):1049-1060. - (5) Costa J.B.D., Wolf G., Sousa J.C. \& Costa F.P. 1992. Suplementação mineral de novilhas neloradas em solo arenoso de mata e pastagens de capim-colonião. Pesq. Agropec.Bras.27(10):1459-1466. - (6) Dayrell M.S. \& Resz F. 1984. Teor de fósforo inorgânico no soro sanguíneo de vacas em lactação da região da Zona da Mata. Pesq.Agropec.Bras.19(10):1307-1312. - (7) Fichtner S.S., Paula A.N. \& Viana H.A. 1987. Determinação das carências minerais em bovinos no Estado de Goiás. I. Zinco, cobalto, ferro e manganês. Anais da XXIV Reunião Anual da SBZ, 26 a 31 de julho, Brasília, p. 145. Resumo. - (8) Guimarães A.M., Saliba E.O.S., Rodriguez N.M. \& Moreira P.K. 1992. Variação sazonal de vitamina A, macro e microelementos no capim, plasma e fígado de novilhas Nelore, criadas em pastagens de capim braquiária (Brachiaria decumbens). Arq.Bras.Med.Vet.Zootec.44(1):57-66. - (9) Lisbôa J.A.N., Kuchembuck M.R.G., Kohayagawa A., Bomfim S.R.M., Santiago A.M.H. \& Dutra I.S. 1996. Resultados de patologia clínica e dosagens de elementos minerais em bovinos acometidos pelo botulismo epizoótico no Estado de São Paulo. Pesq.Vet.Bras.16(4):91-97. (10) Lucci C. S., Moxon A.L., Zanetti M.A., Fukushima R.S., Schalch E. \& Pettinati R.L. 1984a. Selênio em bovinos leiteiros no Estado de São Paulo. I. Níveis de selênio em soros sanguíneos. Revta Fac.Med.Vet.Zootec.USP, São Paulo, 21(1):65-70. - (11) Moraes S.S. 1986. Untersuchungen zu Abhängigkeiten der Zink-, Mangan- und Selengehalte in Lebern von Rindern aus ausgewählten Regionen Brasiliens. Dissertation, Hannover. 146p. - (12) Moraes S.S., Silva G.N. \& Döbereiner J. 1994. Microelementos minerais e a "cara inchada" dos bovinos. Pesq.Vet.Bras.14(1):2533. - (13) Moraes S.S. 1998. Avaliação das concentrações de ferro, manganês e ferro no fígado de bovinos e ovinos de várias regiões do Brasil. Pesq.Vet.Bras.18(3/4):107-110.- (14) Moraes S.S., Tokarnia C.H. \& Döbereiner J. 1999. Deficiências de microelementos em bovinos e ovinos em algumas regiões do Brasil. Pesq.Vet.Bras. 19(1):19-33. - (15) Penna A.P., Virgens N.C., Bautista A.R.P.L., Rodrigues F.M., Silva W.G., Costa J.B. \& Suzart J.C.C. 1983. Interação da deficiência de zinco no elo forrageira-bovino, no município de Ipirá, Bahia. Anais da XX Reunião Anual da SBZ, Pelotas, RS. Resumo. - (16) Pott E.B., Brum P.A.R., Almeida I.L., Comastri Filho J.A. \& Dynia J.F. 1987. Nutrição mineral de bovinos de corte no Pantanal Mato-grossense. I. Levantamento de macronutrientes na Nhecolândia (parte central). Pesq.Agropec.Bras.22 (9/10):10931109. - (17) Pott E.B., Almeida I.L., Brum P.A.R., Comastri Filho J.A., Pott A. \& Dynia J.F. 1989a. Nutrição mineral de bovinos de corte no Pantanal Mato-grossense. II. Micronutrientes na Nhecolândia (parte central). Pesq.Agropec.Bras.24(1):109-126. - (18) Pott E.B., Pott A., Almeida I.L., Brum P.A.R., Comastri Filho J.A. \& Tullio R.R.. 1989b. Nutrição mineral de bovinos de corte no Pantanal Mato-grossense. III. Levantamento de macronutrientes no Baixo Piquiri. Pesq.Agropec.Bras.24(11):1361-1368 - (19) Pott E.B., Brum P.A.R., Pott A., Almeida I.L., 
Comastri Filho J.A. \& Tullio R.R. 1989c. Nutrição mineral de bovinos de corte no Pantanal Mato-grossense. IV. Levantamento de micronutrientes no Baixo Piquiri. Pesq.Agropec.Bras.24(11):1369-1380. - (20) Pott E.B., Brum P.A.R., Almeida I.L., Comastri Filho J.A. \& Pott A. 1989d. Nutrição mineral de bovinos de corte no Pantanal Mato-grossense. V. Levantamento de macronutrientes na sub-região de Aquidauana. Pesq.Agropec.Bras.24(11):1381-1395. - (21) Pott E.B., Comastri Filho J.A., Almeida I.L., Brum P.A.R. \& Pott A. 1989e. Nutrição mineral de bovinos de corte no Pantanal Mato-grossense. VI. Levantamento de micronutrientes na sub-região de Aquidauana. Pesq.Agropec.Bras.24(11):1381-1395. - (22) Riet-Correa F., Bondan E.F., Méndez M.C., Moraes S.S. \& Concepción M.R. 1993. Efeito da suplementação com cobre e doenças associadas à carência de cobre em bovinos no Rio Grande do Sul. Pesq.Vet.Bras.13(3/4):45-49.

doença chamam atenção os valores hepáticos muito baixos para Cu e extremamente altos para Fe. (Tokarnia \& Döbereiner 1998)

Também devem ser mencionados os estudos sobre a "doença do peito inchado", enfermidade igualmente de evolução crônica, em bovinos, que se caracteriza por edema da barbela secundário à insuficiência cardíaca. Ela ocorre no leste do Estado de Santa Catarina. Nesta doença os valores hepáticos de Fe são muito elevados e os de Mn baixos. (Tokarnia et al. 1989)

Ainda deve ser destacada a notificação da ocorrência de "morte súbita" em bovinos, cujos valores hepáticos para $\mathrm{Cu}$ foram muito baixos, em região do Estado do Rio Grande do Sul, onde nenhuma planta capaz de causar esses sintomas pode ser responsabilizada. Nessa mesma área a hipomielinogênese congênita em bovinos foi diagnosticada. (Bondan et al. 1991, Riet-Correa et al. 1993).

Um resumo sobre as ocorrências diagnosticadas no Brasil entre 1987 e 1998, consta em uma terceira revisão (Tokarnia et al. 1999). Vide Figura 3.

\section{REFERÊNCIAS}

Barros C.S.L., Barros S.S., Santos M.N. \& Metzdorf L.L. 1988. Miopatia nutricional em bovinos no Rio Grande do Sul. Pesq. Vet. Bras. 8(3/4):51-55.

Bondan E.F., Riet-Correa F. \& Giesta S.M. 1991. Níveis de cobre em fígados de bovinos no sul do Rio Grande do Sul. Pesq. Vet. Bras. 11(3/4):75-80.

Boyazoglu P.A., Barrett E.L., Young E. \& Ebedes H. 1972. Liver mineral analysis as indicator of nutritional adequacy. Proc. 2nd World Conference of Animal Nutrition, Madrid, p. 995-1008.

Brum P.A.R., Sousa J.C., Comastri Filho J.A. \& Almeida I.L. 1987a. Deficiências minerais de bovinos na sub-região dos Paiaguás, no Pantanal Matogrossense. I. Cálcio, fósforo e magnésio. Pesq. Agropec. Bras. 22(9/10):10391048.

Brum P.A.R., Sousa J.C., Comastri Filho J.A. \& Almeida I.L. 1987b. Deficiências minerais de bovinos na sub-região dos Paiaguás, no Pantanal Matogrossense. II. Cobre, zinco, manganês e ferro. Pesq. Agropec. Bras. 22(9/ 10):1049-1060.

Cavalcanti I. 1967. Comunicação pessoal (Min. Agric., Dois Irmãos, Recife, PE).

Conrad J.H. 1984. Administração racional de suplementos minerais a nível de fazenda. I Simpósio sobre Nutrição Mineral, São Paulo, p. 57-67.

Conrad J.H. \& Mendes M.O. 1965. Estudo comparativo do uso de suplementos minerais e fonte de proteína sobre a porcentagem de nascimento de bezerros. Relatório Técnico de Agricultura Brasil-Estados Unidos, Rio de Janeiro. (Citado por Conrad et al. 1984)

Corrêa R. 1955. Carência de cobalto em bovinos no Estado de São Paulo. Revta Bras. Biologia, 15:309-313.

Corrêa R. 1957. Carência de cobalto em bovinos. Arqs Inst. Biológico, São Paulo, 24:199-227.

Cortes P.R. 1969/71. Una etiologia de la borrachera del llano. Revta Ganagrinco, Venezuela, 4 (no. 18), 5 (nos 19, 20, 21, 22), 6 (nos 23, 24), num total de 37 páginas, em sequência descontínua.
Dämmrich K. 1986. Comunicação pessoal (Freie Universität Berlin).

Dayrell M.S., Döbereiner J.\& Tokarnia C.H. 1973a. Deficiência de fósforo em bovinos na região de Brasília. Pesq. Agropec. Bras., Sér. Vet. 8:105-114.

Dayrell M.S., Lopes H.O.S., Sampaio I.B.M. \& Döbereiner J. 1973b. Fatores a serem considerados na interpretação de valores analíticos de fósforo inorgânico no soro sanguíneo de bovinos. Pesq. Agropec. Bras., Sér.Vet. 8:43-47.

Döbereiner J., Tokarnia C.H., Costa J.B.D., Campos J.L.E. \& Dayrell M.S. 1971. "Espichamento", intoxicação de bovinos por Solanum malacoxylon, no pantanal de Mato Grosso. Pesq. Agropec. Bras., Sér. Vet. 6:91-117.

Fichtner S.S., Paula A.N. \& Viana H.A. 1987. Determinação das carências minerais em bovinos no Estado de Goiás. I. Zinco, cobalto, ferro e manganês. Anais da XXIV Reunião Anual da SBZ, 26 a 31 de julho, Brasília, p. 145. (Resumo)

Gióvine N. 1943. Estudo clínico da deficiência de fósforo nos bovinos de Minas Gerais. Arqs Esc.Vet., Belo Horizonte, 1:17-25, 7 fig.

Grunert E. \& Santiago C. 1969. Über den Einfluss von Knochenfuttermehl auf die Fruchtbarkeit von Fleischrindern in Rio Grande do Sul, Brasilien. Zuchthyg. 4:65-71.

Guimarães J.M.A.B. \& Nascimento C.N.B. 1971. Efeito da suplementação mineral sobre a percentagem de nascimento de bezerros em rebanhos de bovinos de corte na Ilha de Marajó. Série: Estudos sobre Bovinos, IPEAN, Belém, Pará, vol. 1 (no. 2), p. 37-51.

Healy W.B. 1974. Ingested soil as a source of elements to grazing animals, p. 448-450. In:Trace Element Metabolism in Animals - 2. University Park Press, Baltimore. (Citado por Conrad et al. 1984).

Healy W.B. \& Ludwig T.G. 1965. Ingestion of soil by sheep in New Zealand in relation to wear of teeth. Nature 208 (5012):806-807.

Kessler A., Prenz Jr A.M., Barcellos J.O.J. \& Mühlbach P.R.F. 1995. Utilização de fontes de fósforo grau fertilizante em nutrição animal (fosfatos de rocha, superfosfatos simples ou triplo, mono e diamônio fosfatos). Levantamento bibliográfico. Depto Zootecnia, Fac. Agronomia, Univ. Fed. Rio Grande do Sul, Porto Alegre. 131 p.

Lopes H.O.S., Fichtner S.S., Jardim E.C., Costa C.P. \& Martins Junior W. 1980a. Composição mineral de amostras de solo, forragem e tecido animal da micro-região Mato Grosso de Goiás - I. Cálcio, fósforo, magnésio e potássio. Arqs Esc. Vet. UFMG, Belo Horizonte, 32(2):161-174.

Lopes H.O.S., Fichtner S.S., Jardim E.C., Costa C.P. \& Martins Junior W. 1980b. Teores de cobre e zinco em amostras de solo, forrageiras e tecido animal da micro-região Mato Grosso de Goiás. Arqs Esc. Vet. UFMG, Belo Horizonte, 32(2):151-159.

Lucci C. S., Moxon A.L., Zanetti M.A., Fukushima R.S., Schalch E. \& Pettinati R.L. 1984. Selênio em bovinos leiteiros no Estado de São Paulo. I. Níveis de selênio em soros sanguíneos. Revta Fac. Med. Vet. Zootec. USP, São Paulo, 21(1):65-70.

McDowell L.R., Conrad J.H., Ellis G.L. \& Loosli J.K. 1983. Minerals for Grazing Ruminants in Tropical Regions. University of Florida, Gainesville. 86 p.

Megale F. 1949. Contribuição ao estudo do bócio congênito nos bezerros, no Estado de Minas Gerais. Arqs Esc.Vet., Belo Horizonte, 2:143-150.

Mendes M.O. 1977. Mineral status of beef cattle in the northern part of Mato Grosso, Brazil, as indicated by age, season, and sampling technique. Dissertation, University of Florida, Gainesville. 236p.

Mendes M.O., Conrad J.H. \& Ammerman C.B. 1981. Teores de minerais em bovinos de corte do Estado de Mato Grosso, Revta Bras. Med. Vet. 4(3):25-30.

Mendes M.O., Conrad J.H., Houser R.H. \& McDowell L.R. 1982. Viabilidade 
técnica de biopsia de fígado na determinação dos teores de certos minerais em bovinos. Arqs Univ. Fed. Rural Rio de J. 5(1):55-60.

Menicucci Sobrinho L. 1943. Carência de fósforo e cálcio nos bovinos. Arqs Esc.Vet., Belo Horizonte, 1:9-15.

Miller W.J. \& Stake P.E. 1974. Uses and limitations on biochemical measurements in diagnosing mineral deficiencies. Proceedings Nutrition Conference for the Feed Industry. Atlanta, Georgia, p. 25-43.

Moraes S.S. 1986. Untersuchungen zu Abhängigkeiten der Zink-, Manganund Selengehalte in Lebern von Rindern aus ausgewählten Regionen Brasiliens. Dissertation, Hannover. 146 p.

Pott E.B., Brum P.A.R., Almeida I.L., Comastri Filho J.A. \& Dynia J.F. 1987. Nutrição mineral de bovinos de corte no Pantanal Mato-grossense. I. Levantamento de macronutrientes na Nhecolândia (parte central). Pesq. Agropec. Bras. 22 (9/10):1093-1109.

Pott E.B., Almeida I.L., Brum P.A.R., Comastri Filho J.A., Pott A. \& Dynia J.F. 1989a. Nutrição mineral de bovinos de corte no Pantanal Mato-grossense. II. Micronutrientes na Nhecolândia (parte central). Pesq. Agropec. Bras. 24 (1):109-126.

Pott E.B., Pott A., Almeida I.L., Brum P.A.R., Comastri Filho J.A. \& Tullio R.R. 1989b. Nutrição mineral de bovinos de corte no Pantanal Mato-grossense. III. Levantamento de macronutrientes no Baixo Piquiri. Pesq. Agropec. Bras. 24 (11):1361-1368.

Pott E.B., Brum P.A.R., Pott A., Almeida I.L., Comastri Filho J.A. \& Tullio R.R. 1989c. Nutrição mineral de bovinos de corte no Pantanal Mato-grossense. IV. Levantamento de micronutrientes no Baixo Piquiri. Pesq. Agropec. Bras. 24 (11):1369-1380.

Pott E.B., Brum P.A.R., Almeida I.L., Comastri Filho J.A. \& Pott A. 1989d. Nutrição mineral de bovinos de corte no Pantanal Mato-grossense. V. Levantamento de macronutrientes na sub-região de Aquidauana. Pesq. Agropec. Bras. 24 (11):1381-1395.

Pott E.B., Comastri Filho J.A., Almeida I.L., Brum P.A.R. \& Pott A. 1989e. Nutrição mineral de bovinos de corte no Pantanal Mato-grossense. VI. Levantamento de micronutrientes na sub-região de Aquidauana. Pesq. Agropec. Bras. 24 (11):1381-1395.

Riet-Correa F., Bondan E.F., Méndez M.C., Moraes S.S. \& Concepción M.R. 1993. Efeito da suplementação com cobre e doenças associadas à carência de cobre em bovinos no Rio Grande do Sul. Pesq. Vet. Bras. 13(3/4):45-49.

Rosa I.V. 1989. Fosfato natural como suplemento de fósforo para bovinos. 1989. Coletânea de Seminários Técnicos 1986/88, Embrapa-CNPGC, p. 59-60.

Rosa I.V. \& Cardoso J.L.A. 1987. Fósforo, fosfato de rocha e fluorose em bovinos. Bol. Pesq. no. 4, Embrapa-CNPGC. 33 p.

Sousa J.C. 1978. Interrelationships among mineral levels in soil, forage and animal tissues on ranches in northern Mato Grosso, Brazil. Dissertation, University of Florida, Gainesville. 277 p.

Sousa J.C. \& Darsie G. 1985. Deficiências minerais em bovinos de Roraima, Brasil. I. Zinco e cobalto. Pesq. Agropec. Bras. 20(11):1309-1316.

Sousa J.C. \& Darsie G. 1986. Deficiências minerais em bovinos de Roraima. II. Ferro e manganês. Pesq. Agropec. Bras. 21(7):763-769.

Sousa J.C., Conrad J.H., Blue W.G. \& McDowell L.R.1979. Inter-relações entre minerais no solo, plantas forrageiras e tecido animal. 1. Cálcio e fósforo. Pesq. Agropec. Bras. 14(4):387-395.

Sousa J.C., Conrad J.H., McDowell L.R., Ammerman C.B. \& Blue W.G. 1980. Inter-relações entre minerais no solo, forrageiras e tecido animal. 2. Cobre e molibdênio. Pesq. Agropec. Bras. 15(3):335-341.

Sousa J.C., Conrad J.H., Blue W.G., Ammerman C.B. \& McDowell L.R. 1981. Inter-relações entre minerais no solo, plantas forrageiras e tecido animal. 3. Manganês, ferro e cobalto. Pesq. Agropec. Bras. 16(5):739-746.

Sousa J.C., Conrad J.H., Mott G.O., McDowell L.R. \& Ammerman C.B. 1982. Inter-relações entre minerais no solo, plantas forrageiras e tecido animal no norte Mato Grosso. 4. Zinco, magnésio, sódio e potássio. Pesq. Agropec. Bras. 17(1):11-20.

Sousa J.C., Gomes R.F.C., Rezende A.M., Rosa I.V., Cardoso E.G., Gomes A., Costa F.P., Oliveira A.R., Coelho Neto L. \& Curvo J.B.E. 1983. Resposta de novilhos nelorados à suplementação mineral em pastagens de capimcolonião. Pesq. Agropec. Bras. 18(3):311-318.

Sousa J.C., Gomes R.F.C., Silva J.M.S. \& Euclides V.P.B. 1985. Suplementação mineral de novilhos de corte em pastagens adubadas de capim-colonião. Pesq. Agropec. Bras., 20(2):259-269.

Sousa J.C., Gonçalves E.M., Viana J.A.C. \& Darsie G. 1986. Deficiências minerais em bovinos de Roraima, Brasil. III. Cálcio e fósforo. Pesq. Agropec. Bras. 21(12):1327-1336.

Sousa J.C., Gonçalves E.M., Viana J.A.C. \& Darsie G. 1987. Deficiências minerais em bovinos de Roraima, Brasil. IV. Magnésio, sódio e potássio. Pesq. Agropec. Bras. 22(1):89-98

Sousa J.C., Nicodemo M.L.F. \& Darsie G. 1989. Deficiências minerais em bovinos de Roraima, Brasil. V. Cobre e molibdênio. Pesq. Agropec. Bras. 24(12):1547-1554.

Sutmöller P., Abreu A.V., Grift J. van der \& Sombroek W.G. 1966. Mineral imbalances in cattle in the Amazon valley. Communication no. 53, Dep. Agric. Res., Amsterdam. 135 p. + tables.

Tokarnia C.H., Canella C.F.C. \& Döbereiner J. 1960. Deficiência de cobre em bovinos no delta do Rio Parnaíba, nos Estados do Piauí e Maranhão. Arqs Inst. Biol. Animal, Rio de J., 3:25-37.

Tokarnia C.H., Döbereiner J., Canella C.F.C. \& Guimarães J.A. 1966. Ataxia enzoótica em cordeiros na costa do Piauí. Pesq. Agropec. Bras. 1:357-382.

Tokarnia C.H. \& Döbereiner J. 1976. Doenças causadas por deficiências minerais em bovinos em regime de campo no Brasil. In: Simpósio Latino-Americano sobre Pesquisa em Nutrição Mineral de Ruminantes em Pastagens, Belo Horizonte, Minas Gerais, p. 298-308.

Tokarnia C.H. \& Döbereiner J. 1978. Diseases caused by mineral deficiencies in cattle raised under range conditions in Brazil, p. 163-169. In: Conrad J.H. \& McDowell L.R. (ed.) Latin American Symposium on Mineral Nutrition Research with Grazing Ruminants, Belo Horizonte, Brazil.

Tokarnia C.H., Döbereiner J. \& Silva M.F. 1979. Plantas Tóxicas da Amazônia a Bovinos e outros Herbívoros. Inst. Nac. Pesq. Amazônia (INPA), Manaus, Amazonas. 95 p.

Tokarnia C.H., Döbereiner J., Couceiro J.E.M. \& Silva A.C.C. 1983. Intoxicação por Palicourea aeneofusca (Rubiaceae), a causa de "mortes súbitas" em bovinos na zona da mata de Pernambuco. Pesq. Vet. Bras. 3(3):75-79.

Tokarnia C.H., Döbereiner J. \& Moraes S.S. 1988. Situação atual e perspectivas da investigação sobre nutrição mineral em bovinos no Brasil. Pesq. Vet. Bras. 8(1/2):1-16.

Tokarnia C.H., Gava A., Peixoto P.V., Stolf L. \& Moraes S.S. 1989. A “Doença do peito inchado" (edema da região esternal) em bovinos no Estado de Santa Catarina. Pesq. Vet. Bras. 9(3/4):73-83.

Tokarnia C.H. \& Döbereiner J. 1998. Sobre o “ronca”, doença de etiologia obscura em bovinos, caracterizada por respiração ruidosa. Pesq. Vet. Bras. 18(3/4):93-98.

Tokarnia C.H., Döbereiner J., Moraes S.S. \& Peixoto P. 1999. Deficiências e desequilíbrios minerais em bovinos e ovinos - revisão dos estudos realizados no Brasil, de 1987 a 1998. Pesq. Vet. Bras. 19. (Em publicação)

Underwood E.J. 1981. The Mineral Nutrition of Livestock. 2nd ed. Commonwealth Agricultural Bureaux, Farnham Royal, England, p. 102-103.

\section{Carlos Hubinger Tokarnia Jürgen Döbereiner Paulo Vargas Peixoto}

Departamento de Nutrição Animal e Pastagem Instituto de Zootecnia Universidade Federal Rural do Rio de Janeiro 23835-000 Seropédica, Rio de Janeiro

Embrapa-CNPAB, Projeto Sanidade Animal 23851-970 Seropédica, Rio de Janeiro 